1998), psychiatrists should be aware of an increased risk of clinical hypothyroidism in their patients taking lithium.

Bocchetta, A., Cherchi, A., Loviselli, A., et al (1996) Six-year follow-up of thyroid function during lithium treatment. Acta Psychiatrica Scandinavica, 94, 45-48.

Dunn, J.T. (1998) The epidemiology and prophylaxis of iodine deficiency worldwide. In Schilddrüse 1997: Henning-Symposium on "Jod und Schilddrüse" (eds C. Reiners \& B.Weinheimer), pp. 3-7. Berlin: de Gruyter.

Dussault, J. H. (1993) lodine intake in Canada. In lodine Deficiency in Europe. A Continuing Concern (eds F. Delange, J. T. Dunn \& D. Glinoer), p. I3I. New York: Plenum.

Johnston, A. M. \& Eagles, J. M. (1999) Lithiumassociated clinical hypothyroidism. Prevalence and risk factors. British Journal of Psychiatry, I75, 336-339.

Kirov, G. (1998) Thyroid disorders in lithium-treated patients. Journal of Affective Disorders, 50, 33-40.

Laurberg, P., Pedersen, K. M., Hreidarsson, A., et a (1998) lodine intake and the pattern of thyroid disorders: a comparative epidemiological study of thyroid abnormalities in the elderly in Iceland and in Jutland, Denmark. Journal of Clinical Endocrinology and Metabolism, 83, 765-769.

Leutgeb, U. (1999) Overt hypothyroidism and goitre during prophylactic lithium treatment: the influence of ambient iodine supply. A critical review. Neurology, Psychiatry and Brain Research, 7, 121-130.

Shopsin, B., Shenkman, L., Blum, M., et al (1973) lodine and lithium-induced hypothyroidism. Documentation of synergism. American Journal of Medicine, 55, 695-699.

U. Leutgeb The Practice "Rotmaintal" for the Treatment of Affective and Anxiety Disorders, Bayreuther Strasse 15, 95500 Heinersreuth b. Bayreuth, Germany

\section{Consent in mandatory homicide inquiries}

Since 1994, an independent inquiry has been required in all cases of homicide by discharged psychiatric patients (Department of Health, 1994) and health authorities have needed to develop local procedures for terms of reference for inquiry teams. Methodological inconsistencies have been highlighted (Buchanan, 1999) but the definition of the process of obtaining consent from the patient involved (to allow the inquiry team access to their medical and other relevant case notes) has been neglected.

Issues regarding consent and capacity are assuming ever-increasing importance in clinical practice. Psychiatrists routinely assess this with respect to consent to medication, and rigorous safeguards exist to ensure patients understand their right to withhold or refuse consent. However in the case of homicide inquiries there are neither guidelines nor consensus. According to the terms of reference for homicide inquiries (Department of Health, 1994) it is the responsibility of the health authority to obtain consent. In order do identify current practice, we wrote to 22 health authorities that had commissioned homicide inquiries. Details of the procedures/process used by inquiry teams to obtain consent (and a copy of the actual consent form used) were requested.

Only 11 responses were received, seven providing a copy of the consent form used. These were broadly similar, requesting consent for access to all records (health, social services, probation and housing). Only one reply explicitly stated assessment of capacity. Two authorities did not know how consent was obtained and suggested we contact the psychiatrist on the inquiry team. All respondents included the terms of reference and procedures issued to the inquiry team. None of these mentioned how consent was obtained. A variation in practice for obtaining consent was evident; consent forms were directed through solicitors, prison medical officers and inquiry psychiatrists. Only two consent forms explained that reports would be compiled and published.

Our limited study demonstrates that the important issue of consent appears to have been neglected, which is surprising as inquiry reports rely on full access to medical notes. It is of concern that none of the health authorities could demonstrate adequate procedures for obtaining valid consent. This raises the issue of what patients understand they are consenting to when they sign consent forms to release their records to an inquiry. Understanding fully the consequences of an inquiry (some of which is inevitably negative) is a difficult conceptual task. It is, therefore, most important that patients are presented with clear and comprehensive detail (e.g. with sufficient time allowed to consider the information, explanation of the right subsequently to withdraw consent and that the report will be published). The procedure should be conducted in accordance with the British Medical Association (BMA) guidelines; thus, patients must be able to understand and retain the main benefits and possible risks, be shown to believe that information and be capable of weighing-up the information in order to make a choice (BMA \& The Law Society, 1995). We recommend that health authorities adopt and expand the BMA guidelines to ensure they obtain informed valid consent.

Although it is not the responsibility of the patient's current responsible medical officer to assess the capacity of the patient to give consent, we believe it should be good practice to do so. If this procedure is followed, there is a risk of an increasing proportion of patients refusing to consent to the release of confidential information. If no guidelines exist for health authorities in such circumstances, the whole inquiry process might grind to a halt. Finally, we raise the legal spectre that if valid consent cannot be obtained by health authorities, that they may subsequently be accused of breaking patient confidentiality and be open to a legal challenge from patients who have been subjects of homicide inquiries.

The value of continuing mandatory local inquiries is an important debate but before further inquiries are commissioned we propose that issues surrounding the process and extent of consent be better clarified in the interests of both patients and health professionals.

British Medical Association \& The Law Society (1995) Assessment of Mental Capacity - Guidance for Doctors, p. 66. London: BMA.

Buchanan, A. (1999) Independent inquiries into homicide. British Medical Journal, 318, 1089-1090.

Department of Health (1994) Guidance on the Discharge of Mentally Disordered People and their Continuing Care in the Community. HSE (94) 27. London: Department of Health.

H. Rees Yate Health Centre, 2I West Walk, Yate Bristol BS37 4AX

A. Lillywhite Fromeside Clinic, Blackberry Hill, Stapleton, Bristol BSI6 IED

\section{Medical roles in mental health review tribunals}

Richardson \& Machin (2000) draw attention to the dual role imposed on the medical member of mental health review tribunals (MHRTs), and to the fact that, having made a preliminary examination, they are unlikely to come to a tribunal hearing with an open mind as to whether or not the patient should continue to be detained.

Having served on a great many tribunals, I can say that tribunal members understand that they must reach their decision on what they read in the reports presented to them, 
and what is said, in front of them, by the witnesses (including the patient) at the tribunal hearing. Anything that the patient may have said to the medical member at the preliminary medical examination is not evidence, unless it is reproduced at the hearing, and must not be taken into account.

Medical members, not having heard the views of the responsible medical officer and social worker expressed, have not necessarily formed a view of what the tribunal outcome should be before they arrive at the hearing. Moreover, there is nothing in the tribunal rules that says the medical member should discuss or even reveal what he discovered at the time of his examination of the patient, and on occasion I have refused to do so, as such discussion would clearly influence the other members' final decision.

The advantages of the preliminary examination are that it assists the medical member to ask the most appropriate questions at the hearing, and gives him or her the opportunity to peruse the clinical notes, which may contain important information not available in the reports. The disadvantage is that the preliminary examination is time-consuming, particularly if there is much travelling involved, and there are insufficient medical members of MHRTs comfortably to cover the work.

Why, 40 years ago, it was thought necessary for the medical member to make a preliminary examination is not clear, but I imagine it was primarily to allow a tribunal member to look at the hospital notes, without ruffling medical feathers. If it were possible for the notes to be made available to the whole tribunal in the half-hour before the hearing, I would have thought that we could dispense with the preliminary medical examination.

Richardson, G. \& Machin, D. (2000) Doctors on tribunals. A confusion of roles. British Journal of Psychiatry, 176, II0-115.

\section{A. C. Gibson 73 Canford Cliffs Road, Poole,} Dorset BHI3 7AH

\section{Possible neuroleptic malignant syndrome with quetiapine}

A 20-year-old man with treatment-resistant schizophrenia developed autonomic instability, hyperpyrexia and clouding of consciousness while on quetiapine. At the time he was maintained on $2.4 \mathrm{~g}$ sulpiride. The young man had been unwell for four years, initially in prison, the last 18 months in hospital. He suffered from a schizophrenic illness which was both severe and refractory. The situation was complicated by severe extrapyramidal side-effects with many antipsychotics and benign idiopathic neutropenia.

Sulpiride was started in March 1999, the dose in July increased to $2.4 \mathrm{~g}$ daily. Quetiapine was added in July 1999, to a dosage of $150 \mathrm{mg}$ b.d. This was increased to $200 \mathrm{mg}$ b.d. at the end of October. Compliance was assured.

In early November the patient developed a tachycardia; therefore, quetiapine was reduced to $150 \mathrm{mg}$ b.d. In late November he was noted to be confused, flushed, tachycardic (130 beats per minute) and pyrexial $\left(37.4^{\circ} \mathrm{C}\right)$. His creatine phosphokinase was $723 \mathrm{IU} / 1$ (range 55-120). There had been no other pharmacological interventions for 20 days.

A diagnosis of early neuroleptic malignant syndrome (NMS) was made. All antipsychotic medication was stopped and his physical symptoms resolved over 72 hours.

All antipsychotics can cause NMS (Bazire, 1999). Sulpiride was introduced in the UK in 1983. Twenty-eight cases of NMS with sulpiride have been reported to the Committee on Safety of Medicines, seven cases with sulpiride alone have been published. Quetiapine was introduced in the UK in 1997. Four cases of NMS have been reported to the Committee on Safety of Medicines, one has been published to date (Whalley et al, 1999).

In this case, quetiapine is the more likely causative agent as the patient had been maintained on sulpiride for many months and the onset of symptoms was preceded by a recent change of quetiapine dosage.

Bazire, S. (1999) Psychotropic Drug Directory, pp. 76-77, 267. Salisbury: Quay Books

Whalley, N., Diaz, P. \& Howard, J. (1999) Neuroleptic malignant syndrome associated with the use of quetiapine (abstract). Canadian Journal of Hospital Pharmacy, 52, II2.

A. K. Stanley The Norvic Clinic, St Andrew's Business Park, Thorpe, Norwich NR7 OHT

J. Hunter Kingfisher House, Hellesdon Hospital, Wensum Meadows, off Hospital Lane, Hellesdon, Norwich NR6 5NB

\section{One hundred years ago}

\section{The Medico-Psychological \\ Association}

THE next general meeting of the MedicoPsychological Association of Great Britain and Ireland has been fixed for Thursday, May 10th, and will be held under the presidency of Dr. J. B. Spence, at 11, Chandos-street, Cavendish-square, W., at 4 P.M. Much interest attaches to Dr. H.
Maudsley's paper on "The New Psychology," which will take the form of critical remarks on the methods and aims of the new psychology, especially in reference to children and psycho-physical research, for not only is the subject an important one, but it is intimated that several psychologists and others interested in metaphysics will take part in the discussion. Dr. A. W.
Campbell has promised to give a microscopic demonstration illustrating the arrangement of nerve fibres and nerve cells in the cerebral cortex of a series of idiots' brains, and Dr. W. J. Koenig will contribute a paper in English on "Pupillary Anomalies in Paralysed and Non-paralysed Idiot Children and their Relation to Hereditary Syphilis." On the evening of the day 